Article

\title{
Four Tick-Borne Microorganisms and Their Prevalence in Hyalomma Ticks Collected from Livestock in United Arab Emirates
}

\author{
Nighat Perveen (D), Sabir Bin Muzaffar (D) and Mohammad Ali Al-Deeb * (D) \\ Department of Biology, College of Science, United Arab Emirates University, Al Ain P.O. Box 15551, United Arab Emirates; \\ 201790740@uaeu.ac.ae (N.P.); s_muzaffar@uaeu.ac.ae (S.B.M.) \\ * Correspondence: m_aldeeb@uaeu.ac.ae; Tel.: +971-3-713-6527
}

check for

updates

Citation: Perveen, N.; Muzaffar, S.B.; Al-Deeb, M.A. Four Tick-Borne Microorganisms and Their Prevalence in Hyalomma Ticks Collected from Livestock in United Arab Emirates. Pathogens 2021, 10, 1005. https:// doi.org/10.3390/pathogens10081005

Academic Editors: Sergio

E. Bermúdez, Victor Montenegro H., José Reck and Abdul Ghafar

Received: 30 May 2021

Accepted: 6 August 2021

Published: 9 August 2021

Publisher's Note: MDPI stays neutral with regard to jurisdictional claims in published maps and institutional affiliations.

Copyright: (c) 2021 by the authors. Licensee MDPI, Basel, Switzerland. This article is an open access article distributed under the terms and conditions of the Creative Commons Attribution (CC BY) license (https:/ / creativecommons.org/licenses/by/ $4.0 /)$.

\begin{abstract}
Ticks and associated tick-borne diseases in livestock remain a major threat to the health of animals and people worldwide. However, in the United Arab Emirates (UAE), very few studies have been conducted on tick-borne microorganisms thus far. The purpose of this cross-sectional DNA-based study was to assess the presence and prevalence of tick-borne Francisella sp., Rickettsia sp., and piroplasmids in ticks infesting livestock, and to estimate their infection rates. A total of 562 tick samples were collected from camels, cows, sheep, and goats in the Emirates of Abu Dhabi, Dubai, and Sharjah from 24 locations. DNA was extracted from ticks and PCR was conducted. We found that Hyalomma dromedarii ticks collected from camels had Francisella sp. (5.81\%) and SFG Rickettsia (1.36\%), which was 99\% similar to Candidatus Rickettsia andeanae and uncultured Rickettsia sp. In addition, Hyalomma anatolicum ticks collected from cows were found to be positive for Theileria annulata (4.55\%), whereas H. anatolicum collected from goats were positive for Theileria ovis (10\%). The widespread abundance of Francisella of unknown pathogenicity and the presence of Rickettsia are a matter of concern. The discovery of T. ovis from relatively few samples from goats indicates the overall need for more surveillance. Increasing sampling efforts over a wider geographical range within the UAE could reveal the true extent of tick-borne diseases in livestock. Moreover, achieving successful tick-borne disease control requires more research and targeted studies evaluating the pathogenicity and infection rates of many microbial species.
\end{abstract}

Keywords: Hyalomma dromedarii; Hyalomma anatolicum; tick-borne pathogens; Francisella; Rickettsia; Theileria annulata; Theileria ovis; livestock

\section{Introduction}

Ticks are hematophagous ectoparasites of a wide range of vertebrate hosts, including humans and animals, that play a significant role in the transmission cycles of various zoonotic diseases caused by viruses, bacteria, and protozoans [1,2]. Mixed tick-borne microorganism infections are common in nature and research and epidemiological investigations suggest that infections caused by mixed tick-borne microbiota can modulate their pathogenicity and disease burden in various hosts [3]. Nevertheless, the incidence of tick-borne infections is increasing in various parts of the world [4,5]. Crimean-Congo hemorrhagic fever (CCHF), rickettsioses, tularemia, anaplasmosis, ehrlichiosis, babesiosis and tropical theileriosis are the most common tick-borne diseases transmitted by the genus Hyalomma in the Middle East and North Africa region (MENA) [6]. The distribution of tick vector species and tick-borne pathogens are continuing to expand and overlap [4]. Multiple factors are involved in the increase in tick-borne diseases in the MENA region including expansion of tick geographic ranges due to wide-ranging livestock farming, import of animals from other geographic regions, an abundance of wildlife populations that support ticks lifecycles, and improved diagnostics and surveillance [6]. Thus, Hyalomma (Acari: Ixodidae) species which are widespread in the MENA region, Southern Europe, Central, Southern and South-Eastern Asia [6-8] pose a serious threat to human and animal health, and food security [6]. 
Francisella tularensis is the causative agent of a zoonotic disease referred to as tularemia, which can be fatal to humans and animals [9]. Transmission to humans occurs by direct contact, inhalation of aerosolized organisms or ingestion of contaminated material(s), or through bites of arthropods such as ticks and mosquitoes [10]. Tularemia occurs in the northern hemisphere and more often in Scandinavia, Russia, northern America, and Japan, however, tularemia has recently been reported from Europe with the highest annual incidence in Kosovo and Turkey and has become a significant re-emerging disease globally [9-11]. In addition, it has been reported from Middle East countries including Iran and Turkey [12]. Small mammals and arthropods, especially ticks (Dermacentor, Amblyomma, Haemaphysalis and Ixodes) play a vital role in the terrestrial cycle of F. tularensis [11,13]. Ticks are significant in the persistence of these bacteria in nature and transmit them to wild animals and livestock. Furthermore, ticks may serve as reservoirs and can carry bacteria in their bodies throughout their lives [11]. Francisella transmission in ticks can occur transtadially [14] as well as transovarially [15]. Several Francisella variants have been detected in ticks. In addition to F. tularensis, closely related bacteria broadly categorized as "Francisella-like endosymbionts" (FLE) may exist widely in ticks. These endosymbionts are assumed to be nonpathogenic to humans and may cause limited pathogenicity in small animals [16]. Francisella-like endosymbionts have been identified in tick species including Dermacentor, Amblyomma, Ornithodoros, Ixodes, and Hyalomma [17-22]. Moreover, they have been reported in the camel tick, Hyalomma dromedarii $[19,23,24]$. Overall, there is a need to determine the pathogenicity of these microbes widely categorized as FLE.

Tick-borne rickettsioses are caused by members of the genus Rickettsia, which are obligate intracellular bacteria belonging to the spotted fever group (SFG) of the order Rickettsiales $[25,26]$. It is worth noting that the Mediterranean spotted fever caused by Rickettsia conorii is found in various Arab countries [6]. In addition, Rickettsia spp. have been reported previously in H. dromedarii ticks [27-29]. Assessment of the pathogenicity of Rickettsia species [30] has shown that species assumed to be nonpathogenic symbionts (e.g., Rickettsia helvetica and Rickettsia slovaca) [26] were actually pathogenic [30].

Piroplasmoses are widespread arthropod-borne infections of domestic and wild vertebrates that are caused by hemoprotozoan parasites of the phylum Apicomplexa that includes four genera: Babesia, Theileria, Cytauxzoon, and Rangelia [5]. Tropical theileriosis is a common tick-borne disease of ruminants including cattle, sheep, and goats, and a major threat to the cattle industry. Several species in the genus Theileria (Piroplasmorida: Theileriidae), for example, cause mortality and economic losses in cattle [31], and to a lesser extent in camels [32]. Theileria are obligate intracellular parasites transmitted by Hyalomma ticks. [32]. Theileria annulata, T. parva, T. lestoquardi, T. luwenshuni, T. ovis, and T. uilenbergi are mainly pathogenic to ruminants [33]. Theileria has been reported from most of the countries in the MENA region [6].

In the United Arab Emirates (UAE), camels were found to be infested with ticks throughout the year [34]; therefore, people who are in close contact with these animals such as farm workers, abattoir workers, veterinarians and researchers are at risk of being exposed to ticks and can have higher chances of getting infections with tick-borne pathogens. The widespread movement of animals in the livestock industry of the UAE suggests that microbes are likely to circulate in farms and periodically emerge as pathogens [6,27]. Thus, the present study was carried out to assess the presence and prevalence of tick-borne Francisella sp., Rickettsia sp., and piroplasmids in ticks infesting livestock using DNA-based methods, and to estimate their infection rates to better understand potential pathogens that threaten the livestock industry of UAE.

\section{Results}

\subsection{Tick Identification}

Ticks were identified as ixodids (Acari: Ixodidae). All ticks collected from camels were identified as $H$. dromedarii, while the ticks which were collected from cows, sheep and goats were identified as $H$. anatolicum, based on known morphological characteristics. 


\subsection{Detection of Francisella}

Francisella sp. DNA was detected using PCR in H. dromedarii ticks from Abu Dhabi. Thirty tick samples had Francisella sp., which was very similar to a Francisella-like endosymbiont based on DNA similarity with the records in GenBank (Supplementary Table S1). A representative sequence was deposited in the GenBank (accession number MW560059). Samples were 98.59\% identical to the Francisella sp. endosymbionts of Amblyomma paulopunctatum (MN998649.1), Dermacentor auratus (JQ764629.1), and Ornithodoros moubata (AB001522.1) (Supplementary Table S1). The phylogenetic tree (Figure 1) was constructed with Francisella sp. of this study and the sequences from the GenBank showing the highest similarity to it. The Francisella sp. DNA sequence of the present study formed a well-defined branch, which was supported by a significant bootstrap value. The overall inter-clade divergence was $0.49 \pm 0.12$ between the Francisella sp. DNA sequence (Abu Dhabi) of this study and the top ten matches from the GenBank. The pairwise genetic distance ranged from 1.44\% (Francisella sp. UAE vs. uncultured Francisella sp. MN998649.1) to 1.68\% (Francisella sp. UAE vs. uncultured Francisella sp. MN998636.1).

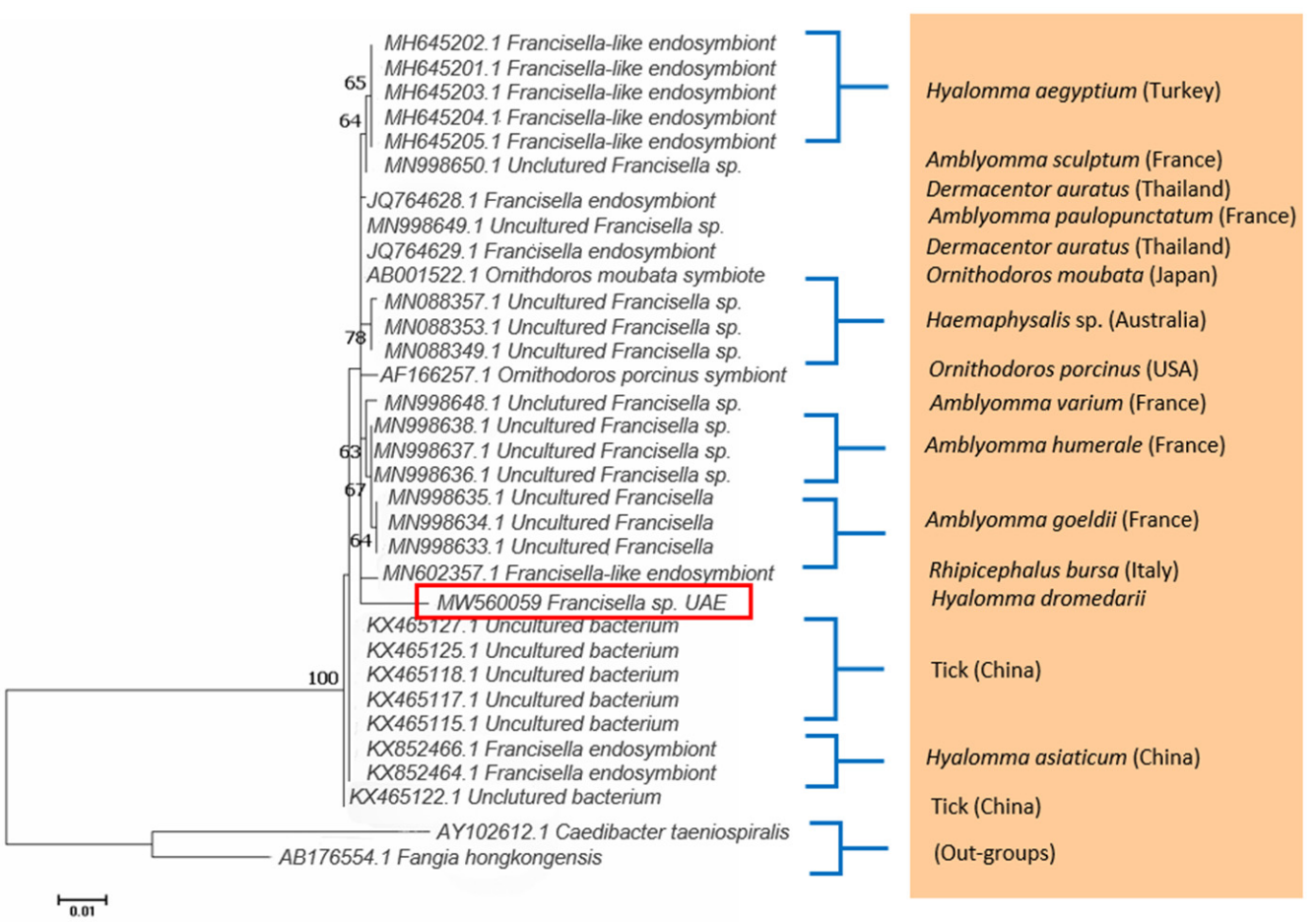

Figure 1. Maximum Likelihood tree based on the $16 \mathrm{~S}$ rRNA gene showing the phylogenetic relationship of Francisella sp. detected in H. dromedarii from camels in Abu Dhabi, with reference sequences from the GenBank database. Caedibacter taeniospiralis and Fangia hongkongensis were used as out-groups. Column shows host names. The tree was generated with MEGA-X [35]. Red rectangle shows the accession number of the UAE sample.

\subsection{Detection of Rickettsia}

Uncultured Rickettsia sp. DNA was only detected in H. dromedarii ticks collected from camels in Abu Dhabi. The 540 bp DNA fragment of the outer membrane protein ompA gene (Figure 2) was not detected in H. dromedarii and H. anatolicum collected from Dubai and Sharjah. Fragments were identified based on DNA sequence similarity with the records of the ompA gene from the GenBank (Supplementary Table S2). A representative sequence of uncultured Rickettsia sp. was deposited in the GenBank (accession number MW701398). This sequence was $99.8 \%$ identical to the Candidatus Rickettsia andeanae detected in Amblyomma parvum (KY628370.1) and Amblyomma tigrinum (KX434737.1) from Brazil, and Amblyomma maculatum from USA (KX158267.1). In addition, the sequence of the present study was $99.8 \%$ identical to uncultured Rickettsia sp. detected in Amblyomma parvum from 
Brazil (MK522488.1), and H. dromedarii from UAE (KF156874.1). The phylogenetic tree (Figure 2), which was constructed using highly similar GenBank sequences of Rickettsia sp. from this study showed that the UAE sample was in a cluster of Cand. R. andeanae and uncultured Rickettsia sp. Furthermore, the Rickettsia sp. was not found in ticks collected from other hosts such as cows, sheep, and goats.

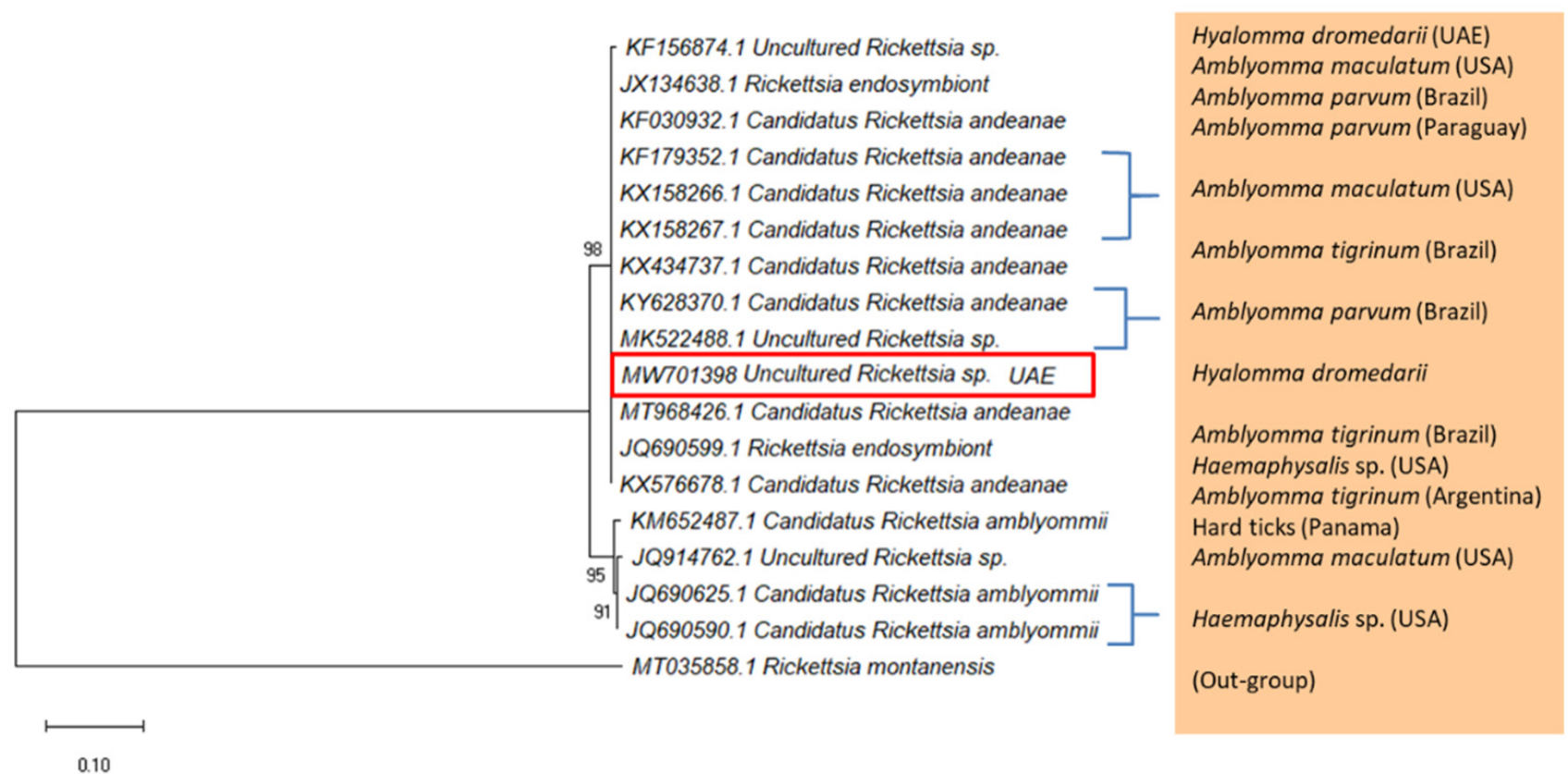

Figure 2. Maximum Likelihood tree based on the ompA gene showing the phylogenetic relationship of uncultured Rickettsia sp. detected in H. dromedarii from camels in Abu Dhabi, with reference sequences from the GenBank database. Rickettsia montanensis was used as an out-group. Column shows host names. The tree was generated with MEGA-X [35]. Red rectangle shows the accession number of the UAE sample.

\subsection{Detection of Piroplasmids}

The DNA of Theileria annulata and T. ovis was detected using PCR in H. anatolicum ticks collected from cows and goats in Sharjah. Fragments of the ssrRNA gene were identified as T. annulata and T. ovis based on DNA similarity with the records in the GenBank (Supplementary Tables S3 and S4, respectively). The sequence of T. annulata was deposited in the GenBank with the accession number MW537791 and the one of T. ovis with MW559557. Samples of T. annulata were $99.62 \%$ identical to the T. annulata detected in cattle, Bos taurus (MT341858.1), ruminants (MT318160.1), and ticks (MN227669.1) (Supplementary Table S3). On the phylogenetic tree of T. annulata (Figure 3), which was constructed using GenBank sequences of high similarity to T. annulata, the UAE sequence appeared in a cluster of T. annulata samples detected from Italy, Pakistan, and Egypt. Similarly, sequences of T. ovis from the UAE were $99.81 \%$ identical to the T. ovis detected in cattle, Bos grunniens (MN394810.1) from China, Tibetan sheep (MN394809.1) from China, and sheep from Iraq (MN712508.1), and Egypt (MN625886.1). The phylogenetic tree (Figure 4) showed that the UAE sequence was in a cluster of T. ovis samples detected from Iraq and Egypt. Finally, piroplasmids were not detected in H. dromedarii and H. anatolicum from Abu Dhabi and Dubai. 


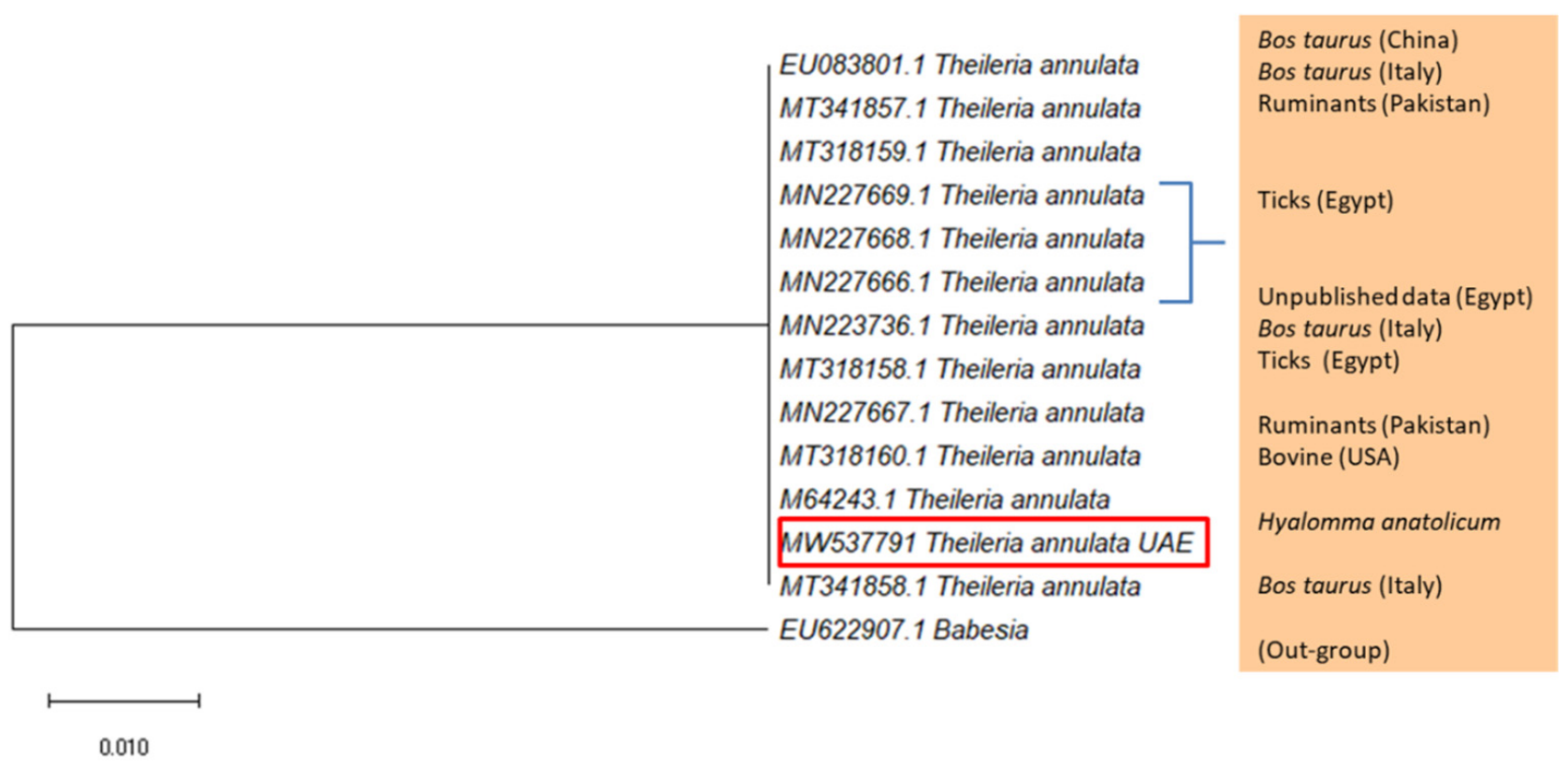

Figure 3. Maximum Likelihood tree based on the ssrRNA gene showing the phylogenetic relationship of T. annulata detected in H. anatolicum collected from cows in Sharjah, with reference sequences from the GenBank database. Babesia major was used as an out-group. Column shows host names. The tree was generated with MEGA-X [35]. Red rectangle shows the accession number of the UAE sample.

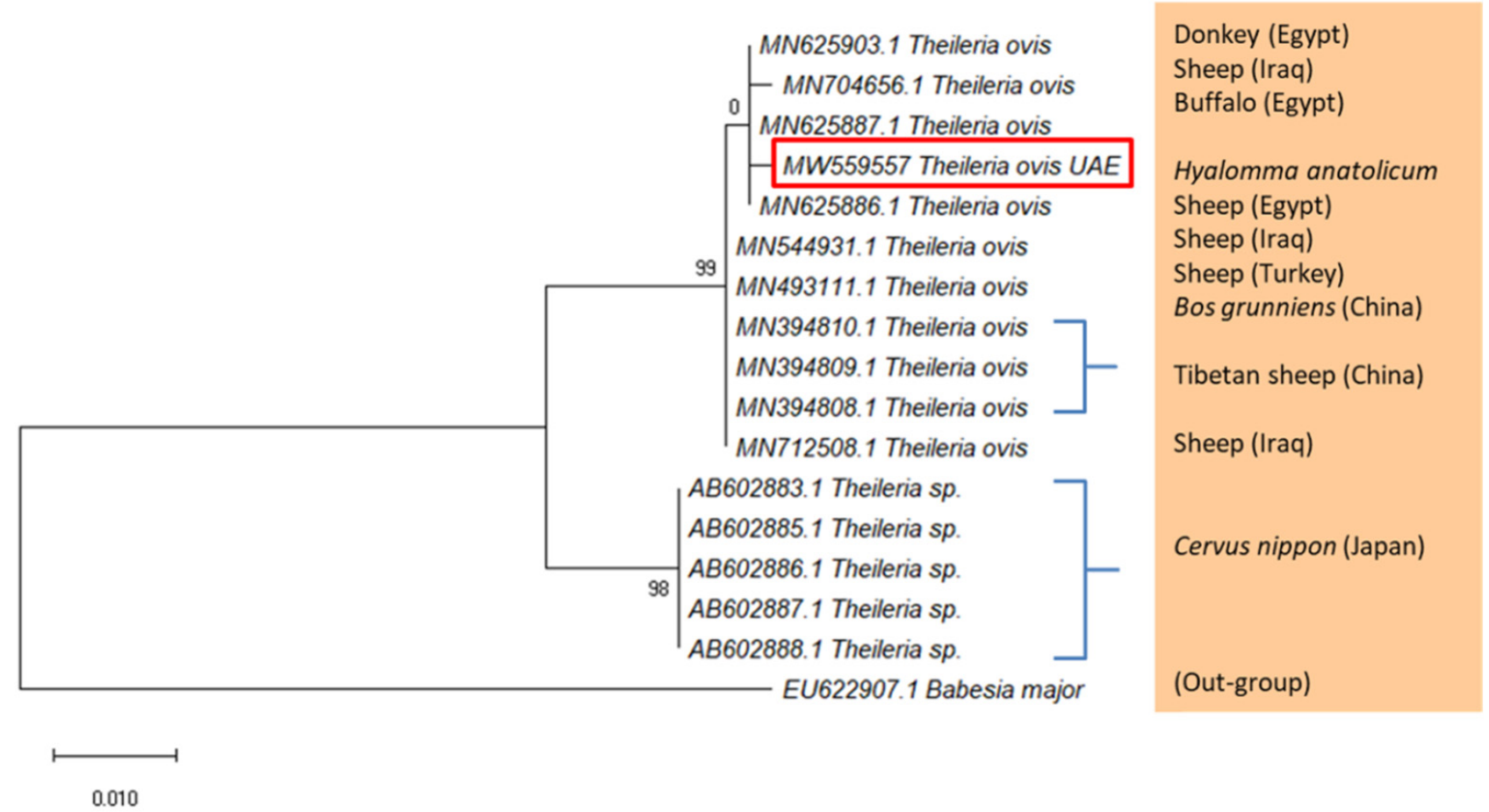

Figure 4. Maximum Likelihood tree based on the ssrRNA gene showing the phylogenetic relationship of T. ovis detected in H. anatolicum collected from goats in Sharjah, with reference sequences from the GenBank database. Babesia major was used as an out-group. Column shows host names. The tree was generated with MEGA-X [35]. Red rectangle shows the accession number of the UAE sample. 


\subsection{PCR-Based Infection Rates of Tick-Borne Microbes}

Tick-borne microbes were detected using PCR in 39 out of 562 DNA samples extracted from ticks, with overall infection rate of $6.94 \%$. In Abu Dhabi, $H$. dromedarii collected from camels contained Francisella sp. (5.81\%) and Rickettsia sp. (1.36\%). However, these microbes were not detected in tick samples from Dubai and Sharjah. In Sharjah, H. anatolicum ticks collected from cows were found to be positive for T. annulata (4.55\%). Moreover, H. anatolicum collected from goats in Sharjah were found to be positive for T. ovis (10\%). No microbe was detected in the ticks collected from sheep in Abu Dhabi, Dubai, and Sharjah. Ticks collected from camels had a higher rate of infection compared with ticks collected from cows, sheep, and goats (Table 1, Supplementary Table S5). In addition, no microbe was detected in ticks collected from camels, cows, sheep and goats in Dubai.

Table 1. Infection rate of bacteria and piroplasmids in ticks collected from livestock in Abu Dhabi, Dubai, and Sharjah, UAE.

\begin{tabular}{|c|c|c|c|c|c|c|c|}
\hline \multirow[t]{2}{*}{ Host } & \multirow[t]{2}{*}{ Tick Species } & \multirow[t]{2}{*}{$\begin{array}{c}\text { Number of } \\
\text { Animals }\end{array}$} & \multirow[t]{2}{*}{$\begin{array}{c}\text { Number of } \\
\text { Samples }\end{array}$} & \multicolumn{4}{|c|}{ Number of Positive Samples (Total Infection Rate) } \\
\hline & & & & Francisella sp. & Rickettsia sp. & T. annulata & T. ovis \\
\hline Camel & H. dromedarii & 518 & 516 & $30(5.81)$ & $7(1.36)$ & $0(0)$ & $0(0)$ \\
\hline Sheep * & H. anatolicum & 70 & 14 & $0(0)$ & $0(0)$ & $0(0)$ & $0(0)$ \\
\hline Goat* & H. anatolicum & 34 & 10 & $0(0)$ & $0(0)$ & $0(0)$ & $1(10)$ \\
\hline Cow * & H. anatolicum & 26 & 22 & $0(0)$ & $0(0)$ & $1(4.55)$ & $0(0)$ \\
\hline Total & & 648 & 562 & 30 & 7 & 1 & 1 \\
\hline
\end{tabular}

\section{Discussion}

Disease detection is the most important step in programs that safeguard human or animal health $[6,36]$. Early detection of pathogens is crucial in curtailing their spread and subsequently in reducing risk of exposure and possible outbreaks [6,36]. Our data revealed the presence of two bacterial and two piroplasmid species in local ticks infesting several animal hosts. Hyalomma ticks contained four microbes, namely, Francisella sp., Rickettsia sp., T. annulata, and T. ovis. We found that the highest infection (5.81\%) was with Francisella sp. in the H. dromedarii ticks collected from camels in Abu Dhabi. These findings are comparable to infection rates of Francisella spp. (4.7\%) in H. dromedarii from camels in Egypt [23]. However, the molecular identification of Francisella sp. in the present study aligned with Francisella-like endosymbionts rather than with any known pathogenic Francisella spp., which agrees with reports from Egypt [23]. In addition, the Francisella sp. of this study was closely related to Francisella endosymbiont recorded in A. paulopunctatum (MN998649.1) [37], D. auratus (JQ764629.1) and O. moubata (AB001522.1). It should be pointed out that previously the genus Francisella has been reported with a very high prevalence (99.1\%) in $\mathrm{H}$. dromedarii ticks from camels in the UAE [24]. Therefore, future studies in the UAE should use species-specific primers to determine whether Francisella sp. is pathogenic or a Francisella-like endosymbiont.

Rickettsia sp. in H. dromedarii ticks collected from camels in Abu Dhabi in our study was closely related to Cand. R. andeanae recorded in Amblyomma ticks from Brazil and the USA. In addition, it was also $99.8 \%$ identical to uncultured Rickettsia sp. detected previously in Amblyomma and Hyalomma ticks from Brazil and the UAE, respectively. Many Rickettsia species exist in ticks, although their pathogenicity has not been determined [38]. Since ticks may serve as vectors as well as reservoirs of rickettsiae in nature, this constitutes a risk factor for Rickettsia transmission in livestock and humans [38]. Spotted fever group (SFG) rickettsiae have at least 30 distinct genotypes in 15 species currently recognized as pathogens in humans [39,40]. Recently, R. parkeri (that causes spotted fever rickettsiosis in humans) and Cand. R. andeanae were reported widely in several tick species across wide geographic regions [40-42]. Although Cand. R. andeanae do not seem to cause human 
infections [43], the high prevalence of Cand. R. andeanae in ticks might interfere with the development of $R$. parkeri and limit its distribution [42]. Therefore, there is a need to better quantify the dynamics among various spotted fever group Rickettsia species within their tick hosts to determine how their interactions contribute towards the epidemiology of rickettsioses in human and animal hosts [43]. Furthermore, ticks are known to engage in symbiotic associations with at least 10 different genera of maternally inherited bacteria [44]. Ticks develop close interactions with beneficial symbionts that provide essential B vitamins and other co-factors required for survival and reproduction [37,44,45]. Coexistence of Francisella and Rickettsia in ticks on camels from Abu Dhabi in our study highlights the need to characterize the interactions between diverse microbes in ticks [24,37].

Theileriosis has a large economic impact at the global level due to losses in the livestock industry [46]. Better control measures like immunization with a live attenuated vaccine has been effectively used to control theileriosis [46]. Many Theileria species have been reported across the MENA region [6]. In this study, we found Theileria spp. in Sharjah only and in low prevalence. This may be due to differences in breeds of livestock, farming conditions and frequency of acaricide application amongst the different Emirates. Theileria ovis is reported here for the first time in $H$. anatolicum ticks from goats in the UAE. The genotype was identical to T. ovis in cattle and sheep from Iraq and Egypt, suggesting that our genotype could be a geographically widespread variant. Theileria annulata detected in cattle in this study was identical to previously identified genotypes from the UAE [27] and clustered with T. annulata from Italy, Pakistan and Egypt, again suggesting that the variant was widespread. The prevalence of Theileria in livestock from Oman [33] and Saudi Arabia is also comparable to our findings [47]. Furthermore, the highest prevalence of Theileria infections occur in $H$. anatolicum compared to H. excavatum, H. scupense and H. marginatum, suggesting that $H$. anatolicum may be the main vector of theileriosis [31]. Thus, the Arabian Peninsula could be a region where theileriosis may become endemic in the future. The presence of Malignant Ovine Theileriosis (MOT) in Oman indicates that mixed species infections are associated with pathogen density regulation (presumably through withinhost interactions), resulting in lower mortality [3]. The role of mixed infections of Theileria pathogens in the epidemiology of ovine theileriosis is required to be investigated for a control strategy and improved clinical outcome [3].

Overall, the findings of the current study highlight that tick-vectored microorganisms continue to be detected repeatedly in the UAE because of the increasing livestock industry and associated tick vectors. Thus, there is a need for annual large-scale disease screening programs. Furthermore, it may be suggested that detailed investigations of the abundance and diversity of these piroplasm pathogens and their mixed infections in vector populations (ticks) need to be performed all over the UAE. In addition, continuous surveillance is imperative to maintain good health of livestock and for the early detection of disease catastrophes in ruminants for food security.

\section{Materials and Methods}

\subsection{Ethics Statement}

Tick collection was carried out in strict accordance with the experimental protocol approved by the Animal Research Ethics Committee of the UAE University (ethical approval\# ERA_2019_5953). We confirm that all methods were carried out in accordance with relevant guidelines and regulations.

\subsection{Study Area, Tick Collection and Identification}

This is a cross-sectional study in which tick collection was done from January 2019 to February 2020. A total 562 tick samples were collected from camels, cows, sheep and goats in the Emirates of Abu Dhabi, Dubai, and Sharjah from 24 locations (Supplementary Table S5; Figure 5). The largest number of ticks was collected from camels (516 samples), which represented the main animal in this study, whereas less samples were collected from sheep, goats, and cows (46 samples). Animals were selected randomly, and from each host 10 ticks 
were removed manually using a pair of forceps. Ticks were collected in $50 \mathrm{~mL}$ plastic tubes (Sterilin, Teddington, UK). All tick samples were placed in an icebox and transported to the Entomology Laboratory at the UAE University. Ticks were frozen at $-20^{\circ} \mathrm{C}$ until further processing. In Sharjah, a pool of ticks was created for each host (camels (3), sheep (25), goats (25), and cows (6)) (Supplementary Table S5). Similarly, a pool of ticks was created from the sheep (36) samples in Abu Dhabi. Further, a total of 15 cows (Australian origin) and 30 goats (Pakistani and Indian origin) were sampled in Abu Dhabi for tick collection; however, these animals were not infested with ticks (Supplementary Table S5). All ticks were identified at the species level on the basis of their morphology by using taxonomic keys [48,49] (Figure 6).

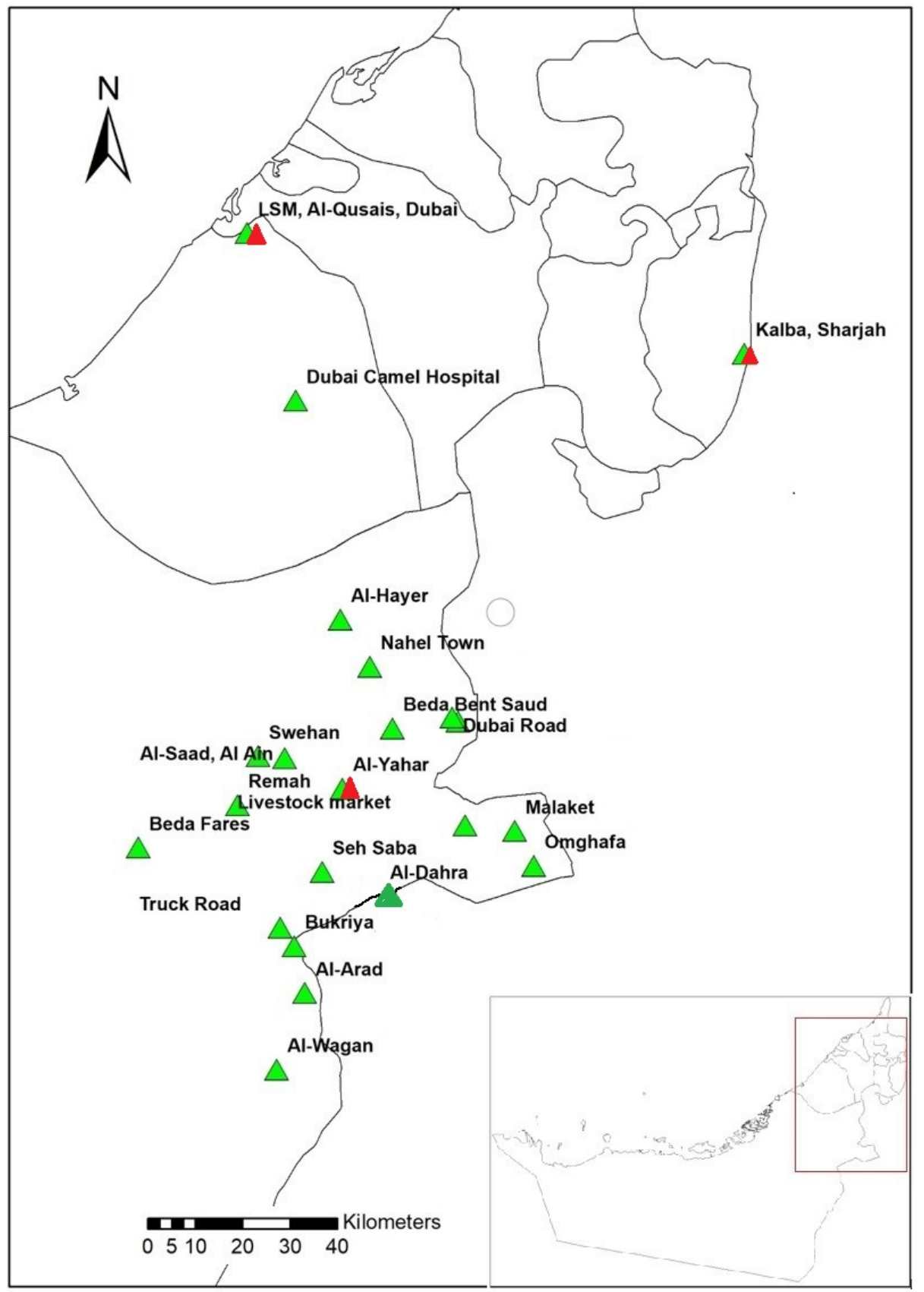

Figure 5. The study area from which tick samples were collected in the UAE; red triangles show the locations of sheep, cows and goats samples, while green triangles show the locations of camel samples except Livestock Market Al-Qusais, Dubai. 


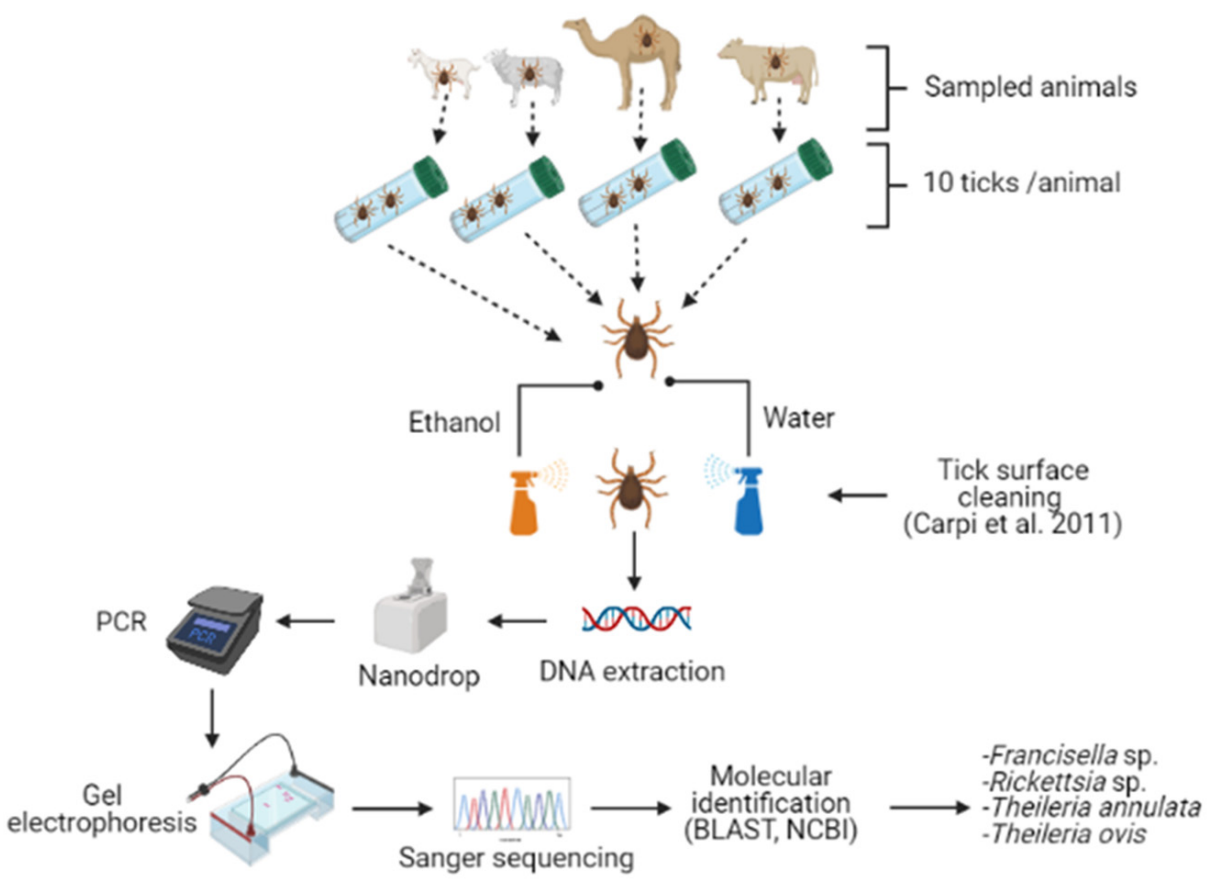

Figure 6. Experimental protocol. Hyalomma ticks $(n=10)$ were collected from each animal (camel, cow, goat, and sheep) from Abu Dhabi, Dubai, and Sharjah in the UAE. The figure was created with BioRender (https:/ / biorender.com/).

\subsection{Genomic DNA Extraction}

As for $H$. dromedarii ticks, DNA was extracted from individual ticks (partially engorged female). However, in the case of H. anatolicum ticks, DNA was extracted from a pool of 5 ticks (male) due to their small size. Further, partially engorged females of $H$. anatolicum were not available in all samples. Before the extraction, each tick was washed in $500 \mu \mathrm{L}$ $70 \%$ ethanol followed by $500 \mu \mathrm{L}$ sterile double-distilled $\mathrm{H}_{2} \mathrm{O}$ for five minutes to remove environmental contaminants attached to the tick body [50] and then dried for $10 \mathrm{~min}$. Ticks were manually crushed using a plastic pellet pestle (Kimble, Fisher Scientific, Waltham, MA, USA) inside a sterile $1.5 \mathrm{~mL}$ micro-centrifuge tube by using liquid nitrogen. The DNeasy blood and tissue kit (Qiagen, Hilden, Germany) was used for tick genomic DNA extraction, following the protocol of the manufacturer. Extracted DNA samples were stored in a freezer at $-80^{\circ} \mathrm{C}$.

\subsection{Polymerase Chain Reaction}

PCR tests were performed for Francisella sp. detection, with tick genomic DNA using an oligonucleotide primer pair (Table 2) [51] to amplify $1151 \mathrm{bp}$ of the 16S rRNA gene. Detection of Rickettsia sp. was carried out by nested PCR of the ompA gene [52]. The amplification of a $590 \mathrm{bp}$ fragment was obtained in the first PCR and the amplification of a $540 \mathrm{bp}$ fragment was obtained in the second PCR using oligonucleotide primers (Table 2). The detection of T. annulata and T. ovis was done by PCR tests with tick genomic DNA using the oligonucleotide primer pair amplifying $560 \mathrm{bp}$ of the ssrRNA gene [53] (Table 2). For all the above-mentioned microorganisms, each PCR reaction was carried out in $25 \mu \mathrm{L}$ volume containing $12.5 \mu \mathrm{L}$ Taq PCR master mix (Qiagen, Hilden, Germany), $1.0 \mu \mathrm{L}(10 \mathrm{pM})$ of each primer, $3.0 \mu \mathrm{L}$ of genomic DNA, and $7.5 \mu \mathrm{L}$ nuclease-free water. PCR amplifications were carried out in a Swift MaxPro thermo-cycler (ESCO, Singapore) according to cycle conditions given in Table 2. Every PCR included a negative control (no template DNA) to detect any contamination. In addition, a positive control was used to indicate that the primers were properly annealing to the target region on the template DNA. In every PCR, we used filter tips and separate $0.2 \mathrm{~mL}$ tubes, rather than a PCR 96-well plate, to avoid aerosol cross-contamination between samples. In addition, PCR reaction 
tubes of the positive controls were prepared in a separate laboratory, to avoid any chance of contamination.

Table 2. Primers and cycle conditions used to amplify gene fragments.

\begin{tabular}{|c|c|c|c|c|c|c|}
\hline Pathogen & $\begin{array}{l}\text { Target } \\
\text { Gene }\end{array}$ & Primer & Sequence $\left(5^{\prime}-3^{\prime}\right)$ & Cycle Conditions & $\begin{array}{l}\text { Amplicon } \\
\text { Size (bp) }\end{array}$ & Reference \\
\hline Francisella sp. & $16 \mathrm{~S}$ rRNA & $\begin{array}{l}\text { Fr153F0.1 } \\
\text { Fr1281R0.1 }\end{array}$ & $\begin{array}{l}\text { GCCCATTTGAGGGGGATACC } \\
\text { GGACTAAGAGTACCTTTTTGAGT }\end{array}$ & $\begin{array}{c}95^{\circ} \mathrm{C} 4 \mathrm{~min} \\
40 \text { cycles: } \\
94{ }^{\circ} \mathrm{C} 30 \mathrm{~s} \\
60^{\circ} \mathrm{C} 45 \mathrm{~s} \\
72^{\circ} \mathrm{C} 60 \mathrm{~s} \\
72^{\circ} \mathrm{C} 20 \mathrm{~min}\end{array}$ & 1151 & {$[51]$} \\
\hline \multirow[t]{2}{*}{ Rickettsia sp. } & \multirow[t]{2}{*}{ ompA } & $\begin{array}{l}\text { RR 190-70 (1st PCR) } \\
\text { RR 190-701(1st PCR) }\end{array}$ & $\begin{array}{l}\text { ATGGCGAATATTTCTCCAAAA } \\
\text { GTTCCGTTAATGGCAGCATCT }\end{array}$ & $\begin{array}{l}94^{\circ} \mathrm{C} 1 \mathrm{~min} \\
35 \text { cycles: } \\
94^{\circ} \mathrm{C} 30 \mathrm{~s} \\
50^{\circ} \mathrm{C} 1 \mathrm{~min}\end{array}$ & 590 & \multirow[t]{2}{*}[52]{} \\
\hline & & $\begin{array}{l}\text { 190-FN1 (nested) } \\
\text { 190-RN1 (nested) }\end{array}$ & $\begin{array}{l}\text { AAGCAATACAACAAGGTC } \\
\text { TGACAGTTATTATACCTC }\end{array}$ & $\begin{array}{l}68^{\circ} \mathrm{C} 4 \mathrm{~min} \\
72{ }^{\circ} \mathrm{C} 20 \mathrm{~min}\end{array}$ & 540 & \\
\hline Theileria sp. & ssrRNA & $\begin{array}{l}\text { Pirop-F } \\
\text { Pirop-F }\end{array}$ & $\begin{array}{l}\text { GTCTTGTAATTGGAATGATGG } \\
\text { CCAAAGACTTTGATTTCTCTC }\end{array}$ & $\begin{array}{c}94^{\circ} \mathrm{C} 2 \mathrm{~min} \\
35 \text { cycles: } \\
94^{\circ} \mathrm{C} 30 \mathrm{~s} \\
50^{\circ} \mathrm{C} 30 \mathrm{~s} \\
72^{\circ} \mathrm{C} 60 \mathrm{~s} \\
72^{\circ} \mathrm{C} 7 \mathrm{~min}\end{array}$ & 560 & [53] \\
\hline
\end{tabular}

\subsection{Agarose Gel Electrophoresis and Amplicon Purification}

Products of PCR reactions were visualized using gel electrophoresis on $1.5 \%$ agarose gel, stained by ethidium bromide. The bands on the gel were visualized and photographed using a gel documentation system (Major Science, Taipei, Taiwan). Amplicons of the positive samples which produced the expected band size were purified using a PCR purification kit (Qiagen, Hilden, Germany) following the manufacturer's protocol and saved for DNA sequencing.

\subsection{DNA Sequencing, Phylogenetic Analysis, and Microorganism Identification}

Purified PCR products were sequenced (Sanger sequencing) at the Biology Department sequencing unit, UAE University. Microorganisms were identified based on sequence analysis using the NCBI BLAST (http:/ / blast.ncbi.nlm.nih.gov/Blast.cgi) analysis tool in the GenBank database (accessed on 13 January 2021) (Figure 6). Sequences were submitted in GenBank and received accession numbers (MW537791, MW559557, MW560059, and MW701398). The DNA sequences of this study were compared with known sequences listed in the GenBank nucleotide sequence databases. The obtained sequences were aligned using the MUSCLE program and the phylogenetic trees were constructed through the Maximum Likelihood approach using Kimura 2-parameter method and bootstrap analyses with 1000 replicates in MEGA X 10.0.5 software [35]. In each phylogenetic analysis, we chose the most suitable substitution model based on the lowest Bayesian Information Criterion scores (BIC). Consequently, after the DNA-based molecular identification of the four microorganisms, the infection rate of each microorganism was calculated from the number of samples from each host.

\section{Conclusions}

In this study, the main finding was that $H$. dromedarii ticks collected from camels had Francisella sp. (5.81\%) and Rickettsia sp. (1.36\%), whereas H. anatolicum ticks collected from cows were found to be positive for T. annulata (4.55\%). Moreover, H. anatolicum collected from goats were positive for T. ovis (10\%). Overall, more research is needed to better understand the microorganisms associated with $H$. dromedarii and H. anatolicum ticks. Moreover, the present study underscores the strong need to implement large-scale disease detection studies in livestock in the UAE. 
Supplementary Materials: The following are available online at https: / www.mdpi.com/article/ 10.3390/pathogens10081005/s1, Table S1: Molecular identification of Francisella sp. endosymbiont isolated from $H$. dromedarii collected from camels in Abu Dhabi, UAE based on DNA similarity between 16S rRNA gene and GenBank species using NCBI BLAST, Table S2: Molecular identification of Uncultured Rickettsia sp. isolated from $H$. dromedarii collected from camels in Abu Dhabi, UAE based on DNA similarity between ompA gene and GenBank species using NCBI BLAST, Table S3: Molecular identification of T. annulata isolated from H. anatolicum collected from cows in Sharjah, UAE based on DNA similarity between ssrRNA gene and GenBank species using NCBI BLAST, Table S4: Molecular identification of T. ovis isolated from H. anatolicum collected from goats in Sharjah, UAE based on DNA similarity between ssrRNA gene and GenBank species using NCBI BLAST, Table S5: Prevalence of microbes in Hyalomma ticks in UAE.

Author Contributions: Conceptualization, M.A.A.-D. and S.B.M.; Methodology, M.A.A.-D. and S.B.M.; Formal Analysis, N.P., M.A.A.-D. and S.B.M.; Investigation, N.P.; Writing-Original Draft Preparation, N.P., S.B.M. and M.A.A.-D.; Writing-Review \& Editing, N.P., S.B.M. and M.A.A.-D.; Visualization, N.P. and M.A.A.-D.; Supervision, M.A.A.-D.; Project Administration, M.A.A.-D.; Funding Acquisition, M.A.A.-D. and S.B.M. All authors have read and agreed to the published version of the manuscript.

Funding: The funding of this study was provided by the UAE University through UPAR grant \# G00002604.

Institutional Review Board Statement: Tick collection was carried out in strict accordance with the experimental protocol approved by the Animal Research Ethics Committee of the UAE University (ethical approval\# ERA_2019_5953). We confirm that all methods were carried out in accordance with relevant guidelines and regulations.

Informed Consent Statement: Not applicable.

Data Availability Statement: Data is contained within the article or Supplementary Material.

Acknowledgments: We thank Amjad Saeed, Ibrahim Mohamed Al Hadi, Asma Al Menhali, Sheikha Hamdan Alshamsi, Maitha Alshamsi, Amna Abdalla Khalfan, Aysha Alneyadi for their help in tick collection, Basam Dahy for assistance in preparation of study area map and Salwa Sultan for administrative assistance. In addition, we thank UAE University Transportation Department for providing vehicles for field work.

Conflicts of Interest: The authors declare no conflict of interest.

\section{References}

1. De la Fuente, J.; Antunes, S.; Bonnet, S.; Cabezas-Cruz, A. Tick-Pathogen Interactions and Vector Competence: Identification of Molecular Drivers for Tick-Borne Diseases. Front. Cell. Infect. Microbiol. 2017, 7, 114. [CrossRef] [PubMed]

2. Pfäffle, M.; Littwin, N.; Muders, S.V.; Petney, T.N. The ecology of tick-borne diseases. Int. J. Parasitol. 2013, 43, 1059-1077. [CrossRef] [PubMed]

3. Awad, H.; Gadalla, A.A.H.; Postigo, M.; Al-Hamidhi, S.; Tageldin, M.H.; Skariah, S.; Sultan, A.A.; Johnson, E.H.; Shiels, B.; Pain, A.; et al. Dynamics and within-host interaction of Theileria lestoquardi and T. ovis among naive sheep in Oman. Sci. Rep. 2020, 10, 19802. [CrossRef] [PubMed]

4. Estrada-Peña, A.; de la Fuente, J. The ecology of ticks and epidemiology of tick-borne viral diseases. Antivir. Res. 2014, 108, 104-128. [CrossRef] [PubMed]

5. Alvarado-Rybak, M.; Solano-Gallego, L.; Millán, J. A review of piroplasmid infections in wild carnivores worldwide: Importance for domestic animal health and wildlife conservation. Parasites Vectors 2016, 9, 538. [CrossRef]

6. Perveen, N.; Muzaffar, S.B.; Al-deeb, M.A. Ticks and Tick-Borne Diseases of Livestock in the Middle East and North Africa: A Review. Insects 2021, 12, 83. [CrossRef]

7. Apanaskevich, D.A.; Horak, I.G. The genus Hyalomma koch, 1844: V. re-evaluation of the taxonomic rank of taxa comprising the H. (Euhyalomma) marginatum koch complex of species (acari: Ixodidae) with redescription of all parasitic stages and notes on biology. Int. J. Acarol. 2008, 34, 13-42. [CrossRef]

8. Capek, M.; Literak, I.; Kocianova, E.; Sychra, O.; Najer, T.; Trnka, A.; Kverek, P. Ticks of the Hyalomma marginatum complex transported by migratory birds into Central Europe. Ticks Tick Borne Dis. 2014, 5, 489-493. [CrossRef]

9. Dennis, D.T.; Inglesby, T.V.; Henderson, D.A.; Bartlett, J.G.; Ascher, M.S.; Eitzen, E.; Fine, A.D.; Friedlander, A.M.; Hauer, J.; Layton, M.; et al. Tularemia as a biological weapon: Medical and public health management. J. Am. Med. Assoc. 2001, 285, 2763-2773. [CrossRef]

10. Ellis, J.; Oyston, P.C.F.; Green, M.; Titball, R.W. Tularemia. Clin. Microbiol. Rev. 2002, 15, 631-646. [CrossRef] 
11. Gürcan, Ş. Epidemiology of tularemia. Balk. Med. J. 2014, 31, 3-10. [CrossRef] [PubMed]

12. Shahsavari, S.; Bannazadeh Baghi, H.; Samadi Kafil, H.; Ebrahimzadeh Leylabadlo, H. Re-emerging tularemia in some Middle East Countries: What are the reasons? Iran. J. Public Health 2018, 47, 305-306.

13. Kılıç, S. Francisella tularensis ve Türkiye'de Tularemi Epidemiyolojisine Genel Bir Bakış. Flora İnfeksiyon Hast. Klin. Mikrobiyoloji Derg. 2010, 15, 37-58.

14. Petersen, J.M.; Mead, P.S.; Schriefer, M.E. Francisella tularensis: An arthropod-borne pathogen. Vet. Res. 2009, 40, 7. [CrossRef]

15. Calhoun, E.L.; Alford, H.I., Jr. Incidence of tularemia and Rocky Mountain spotted fever among common ticks of Arkansas. Am. J. Trop. Med. Hyg. 1955, 4, 310-317. [CrossRef]

16. Keim, P.; Johansson, A.; Wagner, D.M. Molecular epidemiology, evolution, and ecology of Francisella. Ann. N. Y. Acad. Sci. 2007, 1105, 30-66. [CrossRef] [PubMed]

17. Scoles, G.A. Phylogenetic analysis of the Francisella-like endosymbionts of Dermacentor ticks. J. Med. Entomol. 2004, 41, 277-286. [CrossRef]

18. De Carvalho, I.L.; Toledo, A.; Carvalho, C.L.; Barandika, J.F.; Respicio-Kingry, L.B.; Garcia-Amil, C.; García-Pérez, A.L.; Olmeda, A.S.; Zé-Zé, L. Francisella species in ticks and animals, Iberian Peninsula. Ticks Tick Borne Dis. 2016, 7, 159-165. [CrossRef] [PubMed]

19. Azagi, T.; Klement, E.; Perlman, G.; Lustig, Y.; Mumcuoglu, K.Y. Francisella-Like Endosymbionts and Rickettsia Species in Local and Imported Hyalomma Ticks. Appl. Environ. Microbiol. 2017, 83, e01302-17. [CrossRef]

20. Ivanov, I.N.; Mitkova, N.; Reye, A.L.; Hübschen, J.M.; Vatcheva-Dobrevska, R.S.; Dobreva, E.G.; Kantardjiev, T.V.; Muller, C.P. Detection of new Francisella-like tick endosymbionts in Hyalomma spp. and Rhipicephalus spp. (Acari: Ixodidae) from Bulgaria. Appl. Environ. Microbiol. 2011, 77, 5562-5565. [CrossRef] [PubMed]

21. Sun, L.V.; Scoles, G.A.; Fish, D.; O'Neill, S.L. Francisella-like endosymbionts of ticks. J. Invertebr. Pathol. 2000, 76, 301-303. [CrossRef] [PubMed]

22. Machado-Ferreira, E.; Piesman, J.; Zeidner, N.S.; Soares, C.A.G. Francisella-like endosymbiont DNA and Francisella tularensis virulence-related genes in Brazilian ticks (Acari: Ixodidae). J. Med. Entomol. 2009, 46, 369-374. [CrossRef] [PubMed]

23. Ghoneim, N.H.; Abdel-Moein, K.A.; Zaher, H.M. Molecular detection of Francisella spp. among ticks attached to camels in Egypt. Vector Borne Zoonotic Dis. 2017, 17, 384-387. [CrossRef] [PubMed]

24. Perveen, N.; Muzaffar, S.B.; Vijayan, R.; Al-Deeb, M.A. Microbial communities associated with the camel tick, Hyalomma dromedarii: $16 \mathrm{~S}$ rRNA gene-based analysis. Sci. Rep. 2020, 10, 17305. [CrossRef]

25. Parola, P.; Paddock, C.D.; Raoult, D. Tick-borne rickettsioses around the world: Emerging diseases challenging old concepts. Clin. Microbiol. Rev. 2005, 18, 719-756. [CrossRef]

26. Raoult, D.; Roux, V. Rickettsioses as paradigms of new or emerging infectious diseases. Clin. Microbiol. Rev. 1997, 10, 694-719. [CrossRef]

27. Al-Deeb, M.A.; Muzaffar, S.B.; Abu-Zeid, Y.A.; Enan, M.R.; Karim, S. First record of a spotted fever group Rickettsia sp. and Theileria annulata in Hyalomma dromedarii (Acari: Ixodidae) ticks in the United Arab Emirates. Fla. Entomol. 2015, 98, 135-139. [CrossRef]

28. Demoncheaux, J.P.; Socolovschi, C.; Davoust, B.; Haddad, S.; Raoult, D.; Parola, P. First detection of Rickettsia aeschlimannii in Hyalomma dromedarii ticks from Tunisia. Ticks Tick Borne Dis. 2012, 3, 398-402. [CrossRef]

29. Loftis, A.D.; Reeves, W.K.; Szumlas, D.E.; Abbassy, M.M.; Helmy, I.M.; Moriarity, J.R.; Dasch, G.A. Rickettsial agents in Egyptian ticks collected from domestic animals. Exp. Appl. Acarol. 2006, 40, 67-81. [CrossRef]

30. Felsheim, R.F.; Kurtti, T.J.; Munderloh, U.G. Genome sequence of the endosymbiont Rickettsia peacockii and comparison with virulent Rickettsia rickettsii: Identification of virulence factors. PLoS ONE 2009, 4, e8361. [CrossRef]

31. Aktas, M.; Dumanli, N.; Angin, M. Cattle infestation by Hyalomma ticks and prevalence of Theileria in Hyalomma species in the east of Turkey. Vet. Parasitol. 2004, 119, 1-8. [CrossRef]

32. Youssef, S.Y.; Yasien, S. Vector identification and clinical, hematological, biochemical, and parasitological characteristics of camel (Camelus dromedarius) theileriosis in Egypt. Trop. Anim. Health Prod. 2015, 47, 649-656. [CrossRef]

33. Al-Fahdi, A.; Alqamashoui, B.; Al-Hamidhi, S.; Kose, O.; Tageldin, M.H.; Bobade, P.; Johnson, E.H.; Hussain, A.R.; Karagenc, T.; Tait, A.; et al. Molecular surveillance of Theileria parasites of livestock in Oman. Ticks Tick Borne Dis. 2017, 8, 741-748. [CrossRef]

34. Perveen, N.; Muzaffar, S.B.; Al-Deeb, M.A. Population dynamics of Hyalomma dromedarii on camels in the United Arab Emirates. Insects 2020, 11, 320. [CrossRef] [PubMed]

35. Kumar, S.; Stecher, G.; Li, M.; Knyaz, C.; Tamura, K. MEGA X: Molecular evolutionary genetics analysis across computing platforms. Mol. Biol. Evol. 2018, 35, 1547-1549. [CrossRef] [PubMed]

36. Cunningham, A.A.; Daszak, P.; Wood, J.L.N. One health, emerging infectious diseases and wildlife: Two decades of progress? Philos. Trans. R. Soc. B Biol. Sci. 2017, 372,1-8. [CrossRef] [PubMed]

37. Binetruy, F.; Buysse, M.; Lejarre, Q.; Barosi, R.; Villa, M.; Rahola, N.; Paupy, C.; Ayala, D.; Duron, O. Microbial community structure reveals instability of nutritional symbiosis during the evolutionary radiation of Amblyomma ticks. Mol. Ecol. 2020, 29, 1016-1029. [CrossRef] [PubMed]

38. Piotrowski, M.; Rymaszewska, A. Expansion of Tick-Borne Rickettsioses in the World. Microorganisms 2020, 8, 1906. [CrossRef] [PubMed] 
39. Paddock, C.D.; Sumner, J.W.; Comer, J.A.; Zaki, S.R.; Goldsmith, C.S.; Goddard, J.; McLellan, S.L.F.; Tamminga, C.L.; Ohl, C.A. Rickettsia parkeri: A Newly Recognized Cause of Spotted Fever Rickettsiosis in the United States. Clin. Infect. Dis. 2004, 38, 805-811. [CrossRef]

40. Delgado-de la Mora, J.; Sánchez-Montes, S.; Licona-Enríquez, J.D.; de la Mora, D.D.; Paddock, C.D.; Beati, L.; Colunga-Salas, P.; Guzmán-Cornejo, C.; Zambrano, M.L.; Karpathy, S.E.; et al. Rickettsia parkeri and Candidatus Rickettsia andeanae in Ticks of the Amblyomma maculatum Group, Mexico. Emerg. Infect. Dis. 2019, 25, 836-838. [CrossRef]

41. Lee, J.K.; Moraru, G.M.; Stokes, J.V.; Wills, R.W.; Mitchell, E.; Unz, E.; Moore-Henderson, B.; Harper, A.B.; Varela-Stokes, A.S. Rickettsia parkeri and "Candidatus Rickettsia andeanae" in Questing Amblyomma maculatum (Acari: Ixodidae) From Mississippi. J. Med. Entomol. 2018, 54, 476-480. [CrossRef]

42. Noden, B.H.; Roselli, M.A.; Loss, S.R. Rickettsia parkeri and Candidatus Rickettsia andeanae in Amblyomma maculatum Group Ticks Emerg. Infect. Dis. 2020, 26, 2018-2021. [CrossRef]

43. Paddock, C.D.; Denison, A.M.; Dryden, M.W.; Noden, B.H.; Lash, R.R.; Abdelghani, S.S.; Evans, A.E.; Kelly, A.R.; Hecht, J.A.; Karpathy, S.E.; et al. High prevalence of "Candidatus Rickettsia andeanae" and apparent exclusion of Rickettsia parkeri in adult Amblyomma maculatum (Acari: Ixodidae) from Kansas and Oklahoma. Ticks Tick Borne Dis. 2015, 6, 297-302. [CrossRef] [PubMed]

44. Duron, O.; Binetruy, F.; Noël, V.; Cremaschi, J.; McCoy, K.D.; Arnathau, C.; Plantard, O.; Goolsby, J.; Pérez de León, A.A.; Heylen, D.J.A.; et al. Evolutionary changes in symbiont community structure in ticks. Mol. Ecol. 2017, 26, 2905-2921. [CrossRef] [PubMed]

45. Bonnet, S.I.; Binetruy, F.; Hernández-Jarguín, A.M.; Duron, O. The Tick Microbiome: Why Non-pathogenic Microorganisms Matter in Tick Biology and Pathogen Transmission. Front. Cell. Infect. Microbiol. 2017, 7, 236. [CrossRef]

46. Bilgic, H.B.; Aksulu, A.; Bakırcı, S.; Unlu, A.H.; Kose, O.; Hacılarlıoglu, S.; Weir, W.; Karagenc, T. Infection dynamics of Theileria annulata over a disease season following cell line vaccination. Vet. Parasitol. 2019, 265, 63-73. [CrossRef] [PubMed]

47. Alanazi, A.D.; Alouffi, A.S.; Alshahrani, M.Y.; Alyousif, M.S.; Abdullah, H.H.A.M.; Allam, A.M.; Elsawy, B.S.M.; Abdel-Shafy, S.; Alsulami, M.N.; Khan, A.; et al. A report on tick burden and molecular detection of tick-borne pathogens in cattle blood samples collected from four regions in Saudi Arabia. Ticks Tick Borne Dis. 2021, 12, 101652. [CrossRef]

48. Walker, A.R.; Bouattour, A.; Camicas, J.-L.; Estrada-Peña, A.; Horak, I.G.; Latif, A.A.; Pegram, R.G.; Preston, P.M. Ticks of Domestic Animals in Africa: A Guide to Identification of Species; Bioscience Reports: Edinburgh, UK, 2003. ISBN 095451730X.

49. Apanaskevich, D.A.; Schuster, A.L.; Horak, I.G. The Genus Hyalomma: VII. Redescription of all Parasitic Stages of H. (Euhyalomma) dromedarii and H. (E.) schulzei (Acari: Ixodidae). J. Med. Entomol. 2008, 45, 817-831. [CrossRef]

50. Carpi, G.; Cagnacci, F.; Wittekindt, N.E.; Zhao, F.; Qi, J.; Lynn, P.; Drautz, D.I.; Rizzoli, A.; Schuster, S.C. Metagenomic Profile of the Bacterial Communities Associated with Ixodes ricinus Ticks. PLoS ONE 2011, 6, e25604. [CrossRef]

51. Duzlu, O.; Yildirim, A.; Inci, A.; Gumussoy, K.S.; Ciloglu, A.; Onder, Z. Molecular Investigation of Francisella-Like Endosymbiont in Ticks and Francisella tularensis in Ixodid Ticks and Mosquitoes in Turkey. Vector Borne Zoonotic Dis. 2016, 16, 26-32. [CrossRef] [PubMed]

52. Blair, P.J.; Jiang, J.; Schoeler, G.B.; Anaya, E.; Cespedes, M.; Felices, V.; Guevara, C.; Mendoza, L.; Villaseca, P.; Sumner, J.W.; et al. Characterization of Spotted Fever Group Rickettsiae in Flea and Tick Specimens from Northern Peru. J. Clin. Microbiol. 2004, 42, 4961-4967. [CrossRef] [PubMed]

53. Beck, R.; Vojta, L.; Mrljak, V.; Marinculić, A.; Beck, A.; Živičnjak, T.; Cacciò, S.M. Diversity of Babesia and Theileria species in symptomatic and asymptomatic dogs in Croatia. Int. J. Parasitol. 2009, 39, 843-848. [CrossRef] [PubMed] 